Int. J. Dev. Biol. 48: 333-337 (2004)

Developmental Expression Pattern

\title{
EST analysis of mRNAs expressed during embryogenesis in Gallus gallus
}

\author{
ERIKA C. JORGE ${ }^{1}$, CLAUDIA B. MONTEIRO-VITORELLO ${ }^{2}$, HELENA J. ALVES ${ }^{1}$, CLARISSA S. SILVA ${ }^{1}$, \\ RACHEL G. BALAN ${ }^{1}$, MATEUS PATRÍCIO ${ }^{1}$ and LUIZ L. COUTINHO*,1 \\ ${ }^{1}$ Departamento de Zootecnia and 'Departamento de Fitopatologia, Escola Superior de Agricultura 'Luiz de Queiroz', \\ Universidade de São Paulo, São Paulo, Brasil
}

\begin{abstract}
Chicken Expressed Sequence Tags (ESTs) were analyzed to identify genes associated with myogenesis during embryonic development. A total of 6,184 ESTs were generated from three cDNA libraries constructed from whole embryos (Stage 26), somites associated with neural tube (Stage 15), and limb buds (Stages 21, 24 and 26). Clustering and assembly of 4,998 valid ESTs resulted in 2,329 unique sequences with 902 clusters (38.7\%) and 1,427 singletons $(61.3 \%)$. There are more than 400,000 chicken ESTs available at GenBank and we were able to identify 143 novel sequences. From these, 45 sequences found either a human EST homolog or a match with conserved regions among proteins. Most of these sequences were found to be expressed in somites, an important tissue for muscle development and not characterized before. This study revealed the value of micro dissected embryonic libraries for describing gene expression profiles associated with myogenesis and gene discovery.
\end{abstract}

KEY WORDS: myogenesis, morphogenesis, chicken embryo, somite, limb bud

Characterizing Expressed Sequence Tags (ESTs) on a large scale has proven to be an efficient strategy for gene discovery, genome annotation and comparative genomics (Adams et al., 1991; Hatey et al., 1998; Rudd, 2003). Recent progress in genomic research allows numerous questions to be addressed in several areas, including embryonic development. In embryogenesis, the main goal is to understand the molecular mechanisms responsible for correct establishment of diverse structures of an organism. Chicken is an ideal vertebrate model organism for embryology because its development occurs in ovorather than in utero. Chicken has also provided an important model for cancer, immune system and gene regulation studies.

Skeletal muscle formation in vertebrates has been largely used as a model for cell fate determination and differentiation. These events are controlled by precise activation of gene expression at the appropriate time and place (Ludolph and Konieczny, 1995). Precursor skeletal muscle cells in vertebrates originate in somite (Pourquié, 2001). During outgrowth, the somites give rise to both sclerotome (ventrally) and dermomyotome (dorsally). The first myogenic precursor cells arise in the medial lip of dermomyotome, that ultimately give rise to the deep muscles of the back (epaxial musculature). Hypoaxial musculature arises in the lateral lip of dermomyotome by two distinct mechanisms: (1) a non-migrating precursor cells, that immediately differentiate in intercostals muscles and muscle of the body wall; and (2) a migratory cell population, precursor of skeletal musculature of the limbs; diaphragm and tongue (Stockdale et al., 2000; Birchmeier and Brohmann, 2000; Buckingham et al., 2003).

Somites and developing limb buds were selected for this work to identify and categorize the profile of genes expressed during skeletal muscle development in G. gallus, to identify new genes, besides those involved in embryogenesis, and to perform a comparative study with human sequences.

\section{cDNA libraries and sequencing}

A total of 4,998 ESTs (Phred quality $>20$ and at least 200 bp) were considered in our analysis (Table 1). The number of cDNA clones that extended from the start-codon (full-length cDNA) was calculated based on BLASTX analysis, and the frequency in each library was $17.4 \%$ (41 unique sequences) for EM1; 21\% (214) for LB1; and $34.7 \%$ (452) for SM1, suggesting that these clones may contain the complete coding sequence. All 4,998 sequences were deposited in the dbEST division of GenBank (access numbers: CD760792 -

Abbreviations used in this paper: EST, expressed sequence tag; LS, library specific; TIGR, The Institute for Genomic Research.

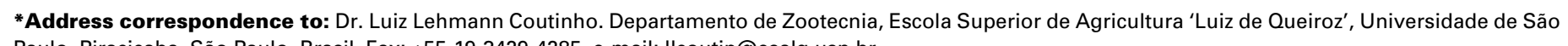
Paulo, Piracicaba, São Paulo, Brasil. Fax: +55-19-3429-4285. e-mail: Ilcoutin@esalq.usp.br

Note: All 4,998 valid EST sequences studied in this paper were deposited in the dbEST division of GenBank (accession numbers: CD760792 - CD765430). 


\section{CD765430).}

\section{Clustering and assembly of ESTs}

Clustering analyses were performed intra-library and inter-library (EM1/LB1/SM1) (Table 1). Most of the clusters from all three libraries were assembled with the alignment of up to four ESTs: 81 (92\%) in EM1; $388(80 \%)$ in LB1; and 361 (88\%) in SM1 (Fig. 1). The number of four ESTs in a cluster has been used as a threshold to calculate redundancy index in other works (Tirunagaru et al., 2000; Jia et al., 2001; Boardmann et al., 2002). Comparable novelty index (56.4\%) was observed for a similar number of ESTs analyzed from other cDNA libraries (Tirunagaru etal., 2000; Jia etal., 2001). The somites library (SM1) had a novelty index of $54.6 \%$ and provided a more diversified mRNA population as compared to limb buds $(P<.0001$, using a chi-square test) and thus, a superior gene discovery rate.

\section{Library-specific ESTs}

EST sequencing from different libraries allows identification of genes putatively transcribed within a certain tissue or during a particular developmental phase. Our analysis revealed 2,090 (89\%) library-specific unique sequences (1,427 singletons and 663 clusters) (Table2). Joint analysis assembled 902 clusters rather than 984 (sum of clusters for each library). The same result was observed among the singletons $(1,427$ instead of 1,569$)$ (Table 2$)$. The level of reorganization among clusters and singletons in the joint analysis is also indicative of low redundancy among libraries.

From the 902 clusters, 321 (ca. 26.5\%) were assembled by ESTs expressed in at least two of the libraries. These common clusters represent ESTs that are concurrently expressed in the different tissues studied. Most of them represent housekeeping genes and

A

EM1 \%

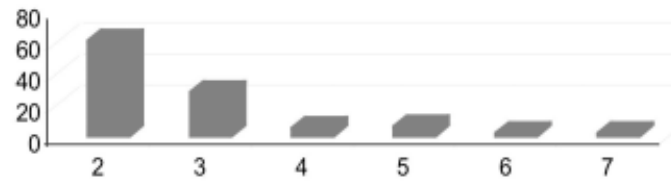

B

Number of ESTs in clusters

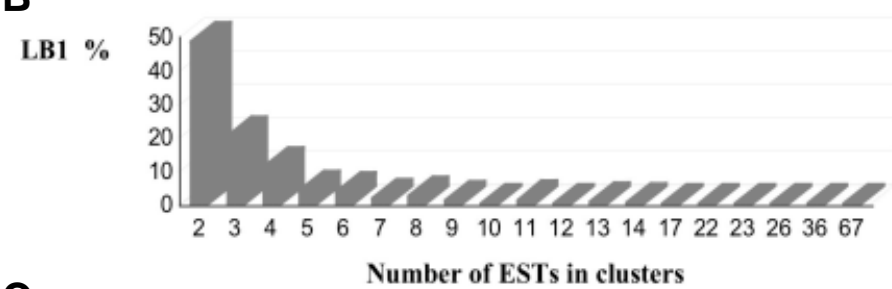

C

SM1

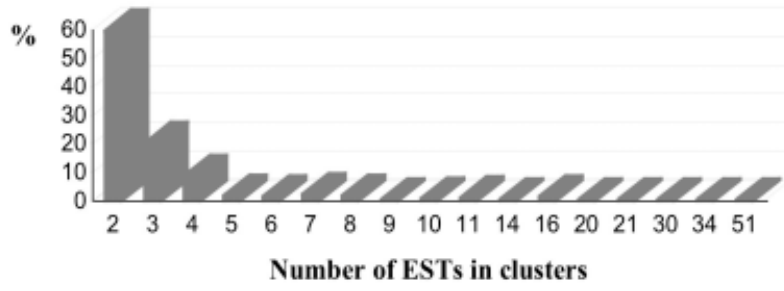

TABLE 1

ANALYSIS OF EACH CDNA LIBRARY (EM1, LB1, SM1) AND ALL DATA GATHERED (EM1 LB1 SM1) REGARDING NUMBER OF ESTS AND CLUSTERIZATION

Total number of valid EST Total number of clusters Number of EST in clusters Total number of singletons Total number of unique sequences Novelty index*

\begin{tabular}{cccc} 
EM1 & LB1 & SM1 & EM1 LB1 SM1 \\
\hline 383 & 2,328 & 2,287 & $\mathbf{4 , 9 9 8}$ \\
88 & 485 & 411 & 902 \\
232 & 1,801 & 1,396 & 3,571 \\
151 & 527 & 891 & 1,427 \\
239 & 1,012 & 1,302 & $\mathbf{2 , 3 2 9}$ \\
$62.4 \%$ & $43.5 \%$ & $54.6 \%$ & $45.7 \%$
\end{tabular}

* Novelty indexes were assessed for each library by calculating the fraction of each library composed of unique sequences (tentative consensus plus singletons) within each library.

subunits of ribosomal proteins. The 663 contigs assembled by ESTs from a single library are divided as: 51 (58\%) specific to EM1; 335 $(69 \%)$ to LB1; and 277 (67\%) to SM1 (Table 2). All singletons identified in joint cluster analysis $(1,427)$ were considered to be library-specific. The level of library-specific unique sequences most likely reflects differential gene expression among tissues analyzed. The specific contribution index indicated that SM1 is the library that contributed to most of the new sequences (Table 2).

\section{Functionalannotation:geneexpression profile of skeletalmuscle precursor cells}

All unique sequences were compared with the protein database of GenBank using BLASTX and were functionally annotated into twelve categories as proposed by TIGR (Fig. 2). A website supplement was created and all detailed information are available at https://maltes.esalq.usp.br/Chicken-Embryo/ (Table A).

From a total of 2,329 unique sequences, 1,474 (63.3\%) were

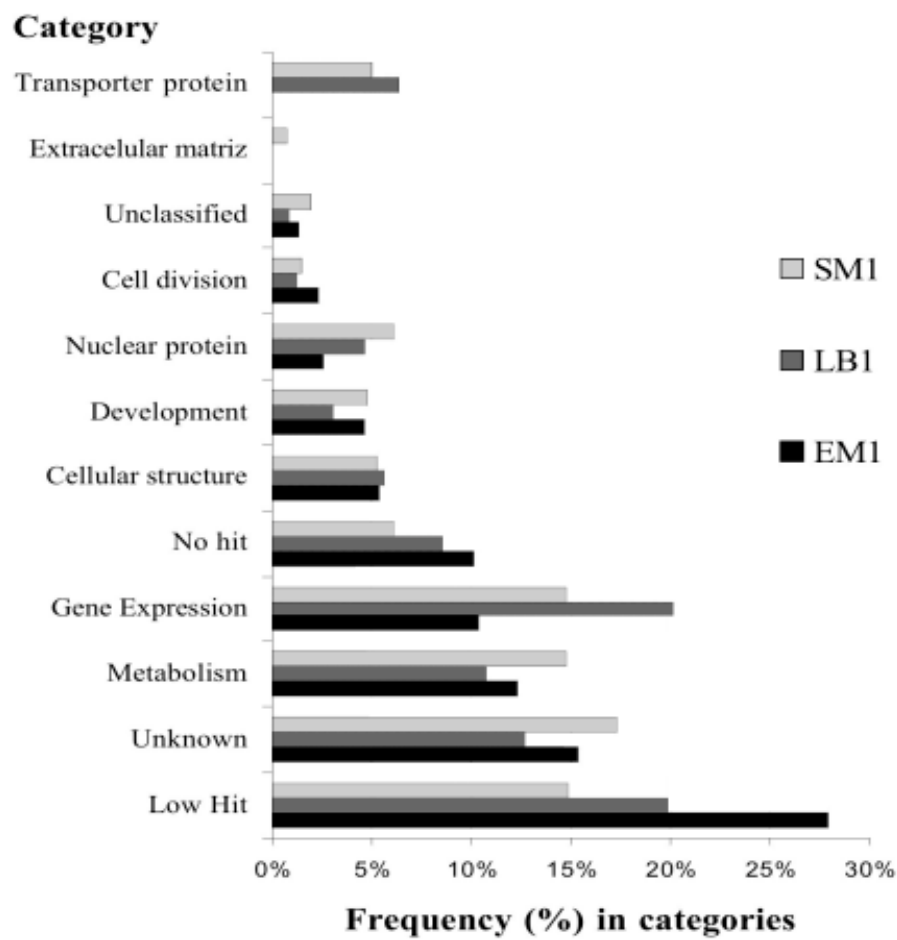

Fig. 1 (Left). Intra-library clustering distribution. Analysis of clusters assembled by Cap3 in (A) EM1 library, (B) LB1 library and (C) SM1 library. Fig. 2 (Right). Functional annotation of the unique chicken sequences into twelve categories as proposed by TIGR. See text for details. 
TABLE 2

IDENTIFICATION OF SEQUENCES SPECIFIC TO A SINGLE CDNA LIBRARY (EM1, LB1, SM1)

\begin{tabular}{llccccc} 
Library & $\begin{array}{l}\text { \# of } \\
\text { clusters }\end{array}$ & LS $^{*}$ clusters & $\begin{array}{c}\text { \# of } \\
\text { singletons }\end{array}$ & $\begin{array}{c}\text { LS }^{*} \\
\text { singletons }\end{array}$ & $\begin{array}{c}\text { \# of LS* unique } \\
\text { sequences }\end{array}$ & $\begin{array}{c}\text { Specific } \\
\text { Contribution** }\end{array}$ \\
\hline EM1 & 88 & $51(58 \%)$ & 151 & $107(70.8 \%)$ & 158 & $3.0 \%$ \\
LB1 & 485 & $335(69 \%)$ & 527 & $471(89.4 \%)$ & 806 & $16.0 \%$ \\
SM1 & 411 & $277(67 \%)$ & 891 & $849(95.3 \%)$ & 1,126 & $22.5 \%$ \\
S & - & 663 & - & 1,427 & 2,090 & - \\
\hline
\end{tabular}

* LS, Library specific; ** Specific contribution was calculated by dividing the number of libraryspecific unique sequences by the total number of ESTs analyzed in the libraries $(4,998)$.

similar to other sequences and 855 (36.7\%) gave either low hit (BLASTX E-value $>10^{-5}$ ) or no hit against that database. Among the most abundant transcripts identified were hemoglobin alpha chain (164 ESTs; $3.2 \%$ ); cytochrome c oxidase (87 ESTs; $1.7 \%$ ); different ribosomal protein subunits (77 ESTs; $1.5 \%$ ); and elongation factor 1 (36 ESTs; $0.7 \%$ ). Most of them grouped into the categories of 'gene expression' ( 12\%) and 'metabolism' ( 15\%) as expected, since these categories include gene products of cellular maintenance.

The 'unknown' category grouped 769 ESTs (average of 15\%). Some of them (28) were clusters composed of more than four ESTs, meaning that they represent highly expressed genes, and were identified as library-specific (data available as Table B of our website). All sequences classified as 'unknown', 'no-hit' and 'lowhit' represent a group of expressed sequences identified in embryonic tissues with no described biological function, and future studies are necessary to determine their function.

Unique sequences that identified homologues with known genes are of special interest due to their association with embryogenesis. The 'development genes' category was composed of 130 unique sequences ( $5 \%$ ) of the three-cDNA libraries (Fig. 2; Table C of the website). Notation data revealed that the profile of genes related to development was different for each of the tissues analyzed, although the expression profile of housekeeping genes was similar. Regarding skeletal muscle formation, myogenic factors (MyoD, Myf5, MRF4 and myogenin) responsible for muscle cell determination and differentiation (Ludolph and Konieczny, 1995), were not identified in the libraries analyzed. The EST analysis of nonnormalized cDNA libraries, which is our case, preferentially, selects for abundant messenger RNAs. Genes often expressed at comparatively low levels, such as myogenic regulators, are only found after exhaustive sequencing. Prior work had determined MyoD to be 100 times less abundant than $\beta$-actin in stages E21E26 chicken embryos (Alvares et al., 2003). In the present study, eleven ESTs $(0.47 \%)$ coding for $\beta$-actin were identified in the LB1 library. This observation indicates that by sequencing less than 3,000 clones, only the more abundant genes are identified. In the SM1 library, no $\beta$-actin EST was identified, while one EST coding for GAPDH was found. These calculations indicate that to find the myogenic factors in our libraries, it would require sequencing about ten times as many EST.

Proteins of the 'Extracellular matrix' were specifically identified in the SM1 library $(14 ; 0.6 \%)$, where they might have a function of adhesion in the spaces between consecutive somites (Bergmann et al., 1995). Proteins that regulate cell cycle represented $2 \%(44)$ of the categorized sequences. Regulation of myoblast cell cycle is an essential pre-requisite for proliferation and correct differen- tiation of muscle fibers (Walsh and Perlman, 1997; Polesskaya and Rudnicki, 2002).

\section{Identification of putative new chicken genes}

One of the major goals of high throughput EST sequencing is gene discovery. Among the 2,329 unique sequences, 143 ( 6\%) were identified as having no hit at protein databases (Table D of the website). This analysis was also performed considering the recent submission of 320,000 chicken ESTs in the GenBank (Boardman et al., 2002). It is known that embryo tissues present a high rate of gene discovery, with similar index of normalized cDNA libraries (Boardman et al., 2002).

Of the 143 putative novel $G$. gallus sequences identified, 41 (29\%) were similar to cDNA clones found at the human dbEST (BLASTN, $E$-value $<10^{-5}, 60 \%$ coverage of the unique sequence). Analysis of reading frame and search for conserved regions performed with Blocks (http://blocks.fhcrc.org/blocks) allowed us to identify 22 different motifs within these sequences (Table 3).

Possible protein variants were identified considering that the

\section{TABLE 3}

NOVEL CHICKEN SEQUENCES THAT FOUND EITHER A HUMAN EST HOMOLOG OR A MATCH WITH CONSERVED REGIONS AMONG PROTEINS USING BLOCKS (HTTP://BLOCKS.FHCRC.ORG/BLOCKS)

\begin{tabular}{|c|c|c|c|}
\hline Clone & GenBank Id & Motifs & E-value \\
\hline GGEZEM1004B02.g & CD763275 & $\mathrm{NCR}^{*}$ & \\
\hline GGEZEM1005A07.g & CD763356 & Tyrosine kinase catalitic domain; & $2.8 \mathrm{E}-05$ \\
\hline GGEZLB1002H11.g & CD763557 & $\mathrm{NCRI}^{*}$ & \\
\hline GGEZLB1002E07.g & CD763520 & CUB domain; & $5.6 \mathrm{E}-12$ \\
\hline GGEZLB1005G12.g & CD763793 & KOG3655: Drebins and related actin binding protein; & $5 \mathrm{E}-53$ \\
\hline GGEZLB1010F04.g & CD764174 & Myristolated alanine rich $C$ kinase; 30 amino acids & $1 \mathrm{E}-10$ \\
\hline GGEZLB1013B10.g & CD764381 & KOG2410: Gamma-glutamyltransferase; & $1 \mathrm{E}-27$ \\
\hline GGEZLB1013D10.g & CD764405 & $\mathrm{NCR} I^{*}$ & \\
\hline GGEZLB1017F09.g & CD764592 & $\mathrm{NCR}^{*}$ & \\
\hline GGEZLB1018G07.g & CD764673 & $\mathrm{NCR}^{*}$ & \\
\hline GGEZLB1019A04.g & CD764693 & Immunoglobulin and major histocompatibility complex $2 ;$ & 4.7E-05 \\
\hline GGEZLB0119H09.g & CD764762 & CXYORF1 protein; & $2 \mathrm{E}-34$ \\
\hline GGEZLB1020H02.g & CD764832 & GG14977-PA & $2 \mathrm{E}-36$ \\
\hline GGEZLB1021H03.g & CD764914 & $\mathrm{NCRI}^{*}$ & \\
\hline GGEZLB1029C04.g & CD765383 & $\mathrm{NCRI}^{*}$ & \\
\hline GGEZSM1002G12.g & CD760951 & RGS-GAIP interacting protein; 68 amino acids & $8 \mathrm{E}-22$ \\
\hline GGEZSM1005C11.g & CD761065 & $N C R I^{*}$ & \\
\hline GGEZSM1007B01.g & CD761195 & PolyC binding protein; & $8 \mathrm{E}-62$ \\
\hline GGEZSM1007F01.g & CD761240 & Hypothetical ptn RIKEN cDNA; & $2 \mathrm{E}-06$ \\
\hline GGEZSM1007H02.g & CD761261 & Alpha-2 macroglobulin family; & $2 \mathrm{E}-36$ \\
\hline GGEZSM1010A10.g & CD761421 & $\mathrm{NCR}^{*}$ & \\
\hline GGEZSM1010A12.g & CD761423 & Hypothetical protein; & $4 \mathrm{E}-51$ \\
\hline GGEZSM1010F05.g & CD761447 & Digeorge syndrome critical region gene $8 ; 70$ amino acids & $7 \mathrm{E}-13$ \\
\hline GGEZSM1011H01.g & CD761539 & Uncharacterized conserved protein; & $6 \mathrm{E}-10$ \\
\hline GGEZSM1014F02.g & CD761769 & Hypothetical protein; & $1 \mathrm{E}-26$ \\
\hline GGEZSM1014G05.g & CD761783 & Unnamed protein product; & $1 \mathrm{E}-75$ \\
\hline GGEZSM1018G03.g & CD761947 & $\mathrm{Na}+$ iodide/Myo_inositol; & $1 \mathrm{E}-19$ \\
\hline GGEZSM1019G11.g & CD762036 & Zinc finger transcription factor; & $1.6 \mathrm{E}-31$ \\
\hline GGEZSM1020C12.g & CD762079 & GABA receptor associated protein; & $5 \mathrm{E}-62$ \\
\hline GGEZSM1023C01.g & CD762320 & Abhydrolase 2 phospholesterase/carboxylesterase & $7 \mathrm{E}-51$ \\
\hline GGEZSM1024E02.g & CD762432 & Seryl tRNA synthetase; & $1 \mathrm{E}-24$ \\
\hline GGEZSM1024H04.g & CD762468 & Hypothetical protein; & $1 \mathrm{E}-05$ \\
\hline GGEZSM1025H05.g & CD762558 & WW domain containing protein 2 - Protein Kinase C; & $5 \mathrm{E}-83$ \\
\hline GGEZSM1026A10.g & CD762575 & $\mathrm{Na}+/ \mathrm{K}+$ ATPase alpha subuint; & $2 \mathrm{E}-98$ \\
\hline GGEZSM1026H11.g & CD762656 & Nuclear protein export factor; & $2 \mathrm{E}-16$ \\
\hline GGEZSM1028E02.g & CD762786 & Chromosome 11 ORF; Uncharacterized conserved protein; & ; $5 \mathrm{E}-57$ \\
\hline GGEZSM1029A07.g & CD762829 & Oligophrenin 1 and related Rho GTPase; & $1 \mathrm{E}-08$ \\
\hline GGEZSM1030F10.g & CD762976 & $\mathrm{NCRI}^{*}$ & \\
\hline GGEZSM1030G09.g & CD762986 & $\mathrm{NCRI}^{*}$ & \\
\hline GGEZSM1030H10.g & CD762997 & KOG2301: Voltage gated Ca2+ channels; & $5 \mathrm{E}-35$ \\
\hline GGEZSM1006G05.g & CD761167 & Dolichyl P Mannose & $1 \mathrm{E}-79$ \\
\hline GGEZSM1011F08.g & CD761525 & Synaptonemal complex protein & $1 \mathrm{E}-43$ \\
\hline GGEZSM1021G01.g & CD762198 & Corticosteroid desydrogenase & $6 \mathrm{E}-44$ \\
\hline GGEZSM1022B01.g & CD762228 & Almstrom syndrome protein & $2 \mathrm{E}-07$ \\
\hline
\end{tabular}

* NCRI, no conserved region identified 
reading frames found in long EST showed high degree of amino acid identity with small regions of large proteins. CD764174 is similar to a myristolated alanine rich $\mathrm{C}$ kinase $(100 \%$ identity, 30 amino acids) and CD761447 is similar to DiGeorge syndrome critical region gene 8 (52\%, 70 amino acids).

Among the 102 (71\%) remaining sequences identified as 'no hit' against the human EST database, we were able to identify conserved motifs in four of them, which are dolichyl $p$ mannose (CD761167); synaptonemal complex protein (CD761525); corticosteroid desydrogenase (CD762198); and almstrom syndrome protein (CD762228) (Table 3). All these 45 sequences (41 that found a match in the human dbEST plus these four sequences showing conserved motifs) probably represent new genes for $G$. gallus and deserve a special attention in future studies. Further experimental analysis have to be performed to consider all the others as new genes as they may represent splice variants which have not been sequenced by other chicken EST projects, artifacts or chimeric EST. Therefore, the strategy to analyze ESTs from specific embryonic tissues or micro dissected-tissues (somites and limb buds) effectively contributed to identification of novel genes.

\section{Comparative analysis}

Comparative genomics allows identification of a subset of highly conserved genes that likely have common functional roles across vertebrate species. Similarity searches using tBLASTx was used to determine sequence conservation between $G$. gallus and Homo sapiens. Approximately $69 \%$ of our collection has a significant match to the human dbEST, considering a tBLASTx $E$ value $<10^{-5}$ and at least $60 \%$ protein sequence coverage. The average identity between $G$. gallus and $H$. sapiens amino acid sequences was $80.3 \%$. No human dbEST match was found for $722(31 \%)$ unique sequences.

Comparative analysis with human dbEST was also conducted among the various functional categories to establish the most evolutionarily conserved groups. Proteins classified in 'Gene expression' and 'Cell structure' categories presented the greatest tBLASTx average identity (86\%), followed by 'Extracellular matrix', 'Cell division' and 'Nuclear proteins' (83\%). 'Developmental' $(81 \%)$ exhibited a larger degree of conservation when compared to 'Metabolism' (77\%) and 'Unknown' (76.3\%).

Among the unique sequences classified in 'Development' category, 93\% (121 unique sequences) found a match with a human orthologue. Fibroblast growth factor receptors (CD763195, CD763444), Bone morphogenic protein 1 (CD763520), as well as other genes with putative function in embryonic development were identified with average identity greater than $85 \%$ (Pourquié, 2001; Buckingham et al., 2003).

Chicken is an important model organism for embryology and development studies and our results reveal the potential to use the sequences expressed in G. gallus to study morphogenesis in other vertebrate species. This is particularly critical for humans due to the ethical and technical difficulties in obtaining embryos or embryonic tissues, such as somites and neural tube. Most of the 5 million human ESTs published to date are from adult tissues (Ko, 2001).

In summary, we have analyzed ESTs obtained from chicken skeletal muscle precursor tissues to determine gene expression profile during myogenesis, to identify novel genes and chicken homologues of known genes. This approach has led to the identification of several genes related to morphogenesis and skeletal muscle development. Although much is known about muscle formation in vertebrates, a collection of genes expressed during the crucial times of muscle cell determination, migration and differentiation was not available for chicken embryos. More importantly, this study revealed the value of micro dissected embryonic libraries for gene discovery.

\section{Experimental Procedures}

\section{Embryo collection of $\mathrm{G}$. gallus and RNA extraction}

Eggs from a broiler-chicken line from Agroceres-Ross (AG-Ross, Tietê, São Paulo, Brazil) were incubated at $37^{\circ} \mathrm{C}$ in a moist atmosphere to obtain embryo stages as defined by Hamburger and Hamilton (1951). Three cDNA libraries were constructed from: (1) whole embryos at stage E26 (6 days; EM1); (2) somites associated with the neural tube at stage E15 (50 hours incubation; SM1); and (3) limb buds in three developmental stages E21, E24 and E26 (3.5 days, 4.5 days and 6 days, respectively; LB1). For the SM1 library, only well-defined somites identified in the stage E15 and the length of neural tube/notochord associated with them were microdissected.

Pools of embryos (10) and microdissected tissues (60 embryos for LB1 and 200 for SM1) were homogenized in Trizol Reagent (Invitrogen Co, Carlsbad, CA, USA) to isolate total RNA. Poly(A)+ RNA was purified using the MessageMaker ${ }^{\circledR}$ Reagent Assembly Kit (Invitrogen), following manufacturer's directions.

\section{cDNA libraries}

cDNA libraries were constructed using 1-2 $\mu \mathrm{g}$ poly $(A)^{+} \mathrm{RNA}$ and the SuperScript Plasmid System kit (Invitrogen) according to manufacturer's protocol. Fractions containing cDNA larger than $500 \mathrm{pb}$ were ligated into pSPORT1 (Invitrogen) at the Sall-Not I site.

\section{Plasmid preparation and sequencing}

Plasmid DNA was purified using a modified alkaline lysis method (Sambrook et al., 1989). Sequencing reactions were conducted using the DYEnamic ET Dye Terminator sequencing kit (Amersham Biosciences, Piscataway, NJ, USA). Clones were sequenced from the 5' end with T7 primer. Sequencing reactions were analyzed on MegaBACE 1000 automated DNA sequencer (Amersham Biosciences).

\section{Data processing}

Base calling, quality control and clustering of the G. gallus ESTs were performed using softwares Phred (Ewing et al., 1998), Cap3 (Huang and Madan, 1999) and Consed (Gordon et al., 1998). All EST sequences with Phred quality greater than 20 and at least 200 bp were considered for clustering. Prior to clustering, vector sequences, adaptors and poly $(A)^{+}$ were identified and screened out (Ewing et al., 1998). Chicken rRNAs, mitochondrial DNA and bacterial contamination were removed from the database.

Sequence similarity searches of the unique sequences were conducted using BLAST programs (Altschul et al., 1990). The GenBank databases used were non-redundant (nr) and dbEST ( $G$. gallus and Homo sapiens). All searches against dbEST were carried out locally. Twelve categories were established for classification of unique sequences according to their putative biological functions based on the ones proposed by The Institute for Genomic Research (TIGR, http:// www.tigr.org): gene expression; metabolism; cell division; extracellular matrix; nuclear proteins; transporter proteins; development; conserved of unknown function; low hit (assuming a BLASTX E-value $<10^{-5}$ ); no hit; and not classified. All data gathered in this project was organized with the database management system MySQL version 3.23.54 (www.mysql.com). Supplementary information is provided in our website (https:// maltes.esalq.usp.br/Chicken-Embryo). 


\section{Acknowledgements}

This work was financed by Fundação de Amparo a Pesquisa do Estado de São Paulo, FAPESP. L.L. Coutinho is a recipient of a research productivity scholarship from Conselho Nacional de Pesquisa, CNPq.

\section{References}

ADAMS, M.D., KELLY, J.M., GOCAYNE, J.D., DUBNICK, M., POLYMEROPOULOS, M.H., XIAO H., MERRIL C.R., WU, A., OLDE, B., MORENO, R.F., KERLAVAGE, A., MCCOMBIE, W.R. and VENTER, J.C. (1991). Complementary DNA Sequencing: Expressed Sequence Tags and Human Genome Project. Science 252: 16511656

ALTSCHUL, S.F., GISH, W., MILLER, W., MYERS, E.W. and LIPMAN, D.J. (1990), Basic local alignment search tool. J. Mol. Biol. 215(3): 403-410.

ALVARES, L.E., MANTOANI, A., GABRIEL, J.E., and COUTINHO, L.L. (2003). Standard-curve competitive RT-PCR quantification of myogenic regulatory factors in chicken embryos. Braz. J. Med. Biol. Res. 36:1629-1641.

BERGMANN, A.D., CHENG, H.J., BRAMBILLA, R., KLEIN, R. and FLANAGAN, J.G. (1995). ELF-2, a new member of the Eph ligand family, is segmentally expressed in mouse embryos in the region of the hindbrain and newly forming somites. Mol. Cell Biol. 15: 4921-4929.

BIRCHMEIER, C. and BROHMANN, H. (2000). Genes that control the development of migrating muscle precursor cells. Curr. Opin. Cell Biol. 12: 725-730.

BOARDMAN, P.E, SANZ-EZQUERRO, J., OVERTON, I.M., BURT, D.W., BOSCH, E. FONG, W.T., TICKLE, C., BROWN, W.R., WILSON, S.A., and HUBBARD, S.J. (2002). A comprehensive collection of chicken cDNAs. Curr. Biol. 12(22): 19651969.

BUCKINGHAM, M., BAJARD, L., CHANG, T., DAUBAS, P., HADCHOUEL, J., MEILHAC, S., MONTARRAS, D., ROCANCOURT, D. and RELAIX, F. (2003). The formation of skeletal muscle: from somite to limb. J. Anat. 202: 59-68.

EWING, B., HILLIER, L., WENDL, M.C. and GREEN, P. (1998). Base-calling of automated sequencer traces using Phred. I. Accuracy Assessment. Genome Res. 8(3): 175-185.

GORDON, D. ABAJIAN, C., and GREEN, P. (1998). Consed: a graphical tool for sequence finishing. Genome Res. 8(3): 195-202.
HAMBURGER, V. and HAMILTON, H.L. (1951). A series of normal stages in the development of the chick embryo. J. Morphol. 88: 49-92.

HATEY, F., TOSSER-KLOPP, G., MARTINATO, C.C., MULSANT, P. and GASSER, F. (1998). Expressed Sequence Tags for Genes: a review. Genet. Sel. Evol. 30 : 521-554.

HUANG, X. and MADAN, A. (1999). Cap3: A DNA sequence assembly program. Genome Res. 9(9): 868-877.

JIA, L., YOUNG, M.F., POWELL, J., YANG, L., HO, N.C., HOTCHKISS, R., ROBEY, P.G. and FRANCOMANO, C.A. (2001). Gene expression profile of human bone marrow stromal cells: high-throughput expressed sequence tag sequencing analysis. Genomics 79: 7-17.

KO, M. (2001). Embryogenomics: developmental biology meets genomics. Trends Biotechnol. 19: 511-518.

LUDOLPH, D.C. and KONIECZNY, S.F. (1995). Transcription factor families: muscling in on the myogenic program. FASEB J. 9(12): 1595-1604.

POLESSKAYA, A. and RUDNICKI, M.A. (2002). A MyoD-dependent differentiation checkpoint: ensuring genome integrity. Dev. Cel/3: 1-2.

POURQUIÉ, O. (2001). Vertebrate Somitogenesis. Annu. Rev. Cell Dev. Biol. 17: 311 . 350.

RUDD, S. (2003). Expressed Sequence Tags: alternative or complement to whole genome sequences. Trends Plant Sci8(7): 321-329.

SAMBROOK, J., FRITSCH, E.F. and MANIATIS, T. (1989). Molecular cloning: a laboratory manual. (ed. Plainview: Cold Spring Harbor Laboratory Press).

STOCKDALE, F.E., NIKOVITS, W.J. and CHRIST, B. (2000). Molecular and cellular biology of avian somite development. Dev. Dyn. 219: 304-321.

TIRUNAGARU, V.G., SOFER, L., CUI, J. and BURNSIDE, J. (2000). An expressed sequence tag database of T-cell enriched activated chicken splenocytes: sequence analysis of 5251 clones. Genomics 66: 144-151.

WALSH, K. and PERLMAN, H. (1997). Cell cycle exit upon myogenic differentiation. Curr. Opin. Genet. Dev. 7: 597-602.

Received: November 2003

Reviewed by Referees: December 2003

Modified by Authors and Accepted for Publication: March 2004 